\title{
Myocardial infarction and angina pectoris in young women
}

\author{
D MANT, L VILLARD-MACKINTOSH, M P VESSEY AND D YEATES \\ From the University of Oxford, Department of Community Medicine and General Practice, Radcliffe Infirmary, \\ Oxford
}

Summary The Oxford-Family Planning Association contraceptive study has now followed 17000 women, predominantly of childbearing age, for a total of more than 200000 woman-years. The incidence of myocardial infarction and angina in women aged less than 50 years has been low: $0.03 / 1000$ woman-years at ages $25-34$ rising to $0.67 / 1000$ woman-years at ages $45-49$. However, the overall incidence in women who were smokers at entry to the study is more than three times that in women who were non-smokers, the increase in individual risk being proportional to the number of cigarettes smoked. Observations on other risk factors must be treated with caution in view of the small numbers involved: in general, the differences and trends reported are not statistically significant. However, a consistent positive relation is observed between incidence rates and both relative weight and parity after adjustment for age and smoking, while no consistent trend is observed for social class. Ever use of oral contraceptives is associated with a twofold increased risk of myocardial infarction (not statistically significant), but there is no increased risk in current users as was suggested by earlier studies. This may reflect the adoption of lower dose preparations and the positive selection of healthy women for oral contraception.

Prospective studies reporting the incidence and aetiology of myocardial infarction and angina pectoris in young women are infrequent. Population based data on cardiovascular disease in women have originated from the Framingham and Health Insurance Plan populations in the United States and from community surveys in Scandinavia and Australia. ${ }^{1-7}$ In a review of the epidemiological literature, Johansson et $a^{8}$ document the annual incidence of myocardial infarction as ranging from 60 to $270 / 100000$ in women aged $50-54$ years and comment that "because of the low incidence of myocardial infarction among women, incidence rates are unreliable below 50 years of age". Moreover, reported incidence rates vary because of differences in populations studied, in definitions of disease, and in completeness of ascertainment. For all these reasons, data from the major prospective studies of contraceptive users which have followed cohorts of young women for a number of years are of particular interest; interim reports on cardiovascular disease in young women have been made by the Walnut Creek group ${ }^{9}$ and by the Royal College of General Practitioners (RCGP). ${ }^{10}$

The Oxford Family Planning Association contraceptive study has now followed 17000 women, predominantly of child bearing age, for a total of more

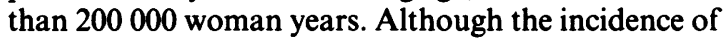
ischaemic heart disease has indeed proved to be low, sufficient data have now accumulated to assess the incidence of acute myocardial infarction and angina pectoris in the study population. It is also possible to assess the influence of smoking, obesity, social class, obstetric history, and contraceptive history, which have been previously identified as risk factors in case-control studies. We report our findings here.

\section{Methods}

The methods used in the study have already been described elsewhere. ${ }^{11}$ A total of 17032 married women aged 25-39 years were recruited on attendance at family planning clinics between 1968 and 1974 . The method of contraception, smoking habit, social class, and medical and obstetric history of each woman were recorded on recruitment. During follow-up, data are recorded on changes in contraceptive method, pregnancies, hospital referrals, and deaths. Discharge summaries are obtained after inpatient hospital stays. Losses to follow-up for reasons other than emigration or death have been at the rate of only about $0.3 \%$ per year. 
This report concerns 25 women diagnosed during follow-up before March 1985 as suffering from myocardial infarction (ICD8 410) and 29 women suffering from angina pectoris (ICD8 413). Diagnostic coding was done initially by one of us (MV) and reassessed by another (DM) at the time of analysis. As far as possible, the reassessment was blind to the patient's contraceptive practice. Account was taken of history, investigations (e.g. electrocardiography, cardiac enzymes, angiography) and treatment. Only the first disease event was included in the analysis: two patients diagnosed as suffering a myocardial infarction following diagnosis of angina were included only in the latter category, as in both cases infarction occurred as a complication of coronary bypass grafting. Three women, in whom myocardial infarction was mentioned on the death certificate but was thought not to be the primary diagnosis, were excluded. Where appropriate, incidence rates were adjusted for age and smoking history (at entry to the study) by indirect standardisation. The confidence intervals given in table 1 were calculated assuming a Poisson distribution (because rare events in large populations can be considered as occurring randomly in time).

In the analysis of oral contraceptive use, the current user group was extended to include women stopping within the six months preceding the disease event to try to ensure that women who stopped because of early symptoms of disease were included. Additionally, for each case, four controls free from ischaemic heart disease were selected who matched the patient on age, date of entry into the cohort, and smoking status, and who were alive and still being followed up at the date the patient was diagnosed as suffering from angina or acute myocardial infarction. The relative risk of cardiovascular disease in relation to oral contraceptive brand was assessed by an unmatched case-control comparison. Contraceptive brands were classified in two categories according to oestrogen content $(<50 \mu \mathrm{g}$ and $\geqslant 50 \mu \mathrm{g}$ ). Progestogen only preparations were included in the former category. Ex-users who had used more than one brand of oral contraceptive were classified according to the brand with the highest oestrogen content.

\section{Results}

The age specific incidence of ischaemic heart disease is shown in table 1. The steep age gradient for both myocardial infarction and angina, which is known to exist in older women, is demonstrated clearly in younger women as well. Table 2 , which gives agev standardised incidence rates, confirms also the strong relation between cigarette smoking and ischaemio heart disease seen in older age groups. There appear $\$$ to be little difference in disease rates between nong smokers and ex-smokers.

Table 1 Age specific incidence of myocardial infarction (MI) and angina pectoris

\begin{tabular}{|c|c|c|c|c|c|c|c|c|c|c|}
\hline \multirow[b]{2}{*}{ Age (yr) } & \multirow[b]{2}{*}{$\begin{array}{l}\text { Woman-yr of } \\
\text { observation }\end{array}$} & \multicolumn{3}{|c|}{$M I$} & \multicolumn{3}{|c|}{ Angina } & \multicolumn{3}{|c|}{ MI or angina } \\
\hline & & $n$ & $\begin{array}{l}\text { Rate/1000 } \\
\text { woman-yr }\end{array}$ & $95 \% C I$ & $n$ & $\begin{array}{l}\text { Rate/1000 } \\
\text { woman-yr }\end{array}$ & $95 \% C I$ & $n$ & $\begin{array}{l}\text { Rate } / 1000 \\
\text { woman-yr }\end{array}$ & $95 \% C I$ \\
\hline $25-34$ & 72366 & 2 & 0.03 & $0 \cdot 00-0 \cdot 10$ & 0 & 0.00 & $0.00 \quad 0.05$ & 2 & 0.03 & $0.00 \quad 0.10$ \\
\hline $35-39$ & 73366 & 4 & 0.05 & $0.01-0.14$ & 7 & 0.09 & 0.040 .20 & 11 & 0.15 & $0.07 \quad 0.27$ \\
\hline $40-44$ & 55139 & 9 & $0 \cdot 16$ & $0.07-0.31$ & 8 & 0.14 & $0.06-0.29$ & 17 & $0 \cdot 31$ & $0.18-0.49$ \\
\hline $50+$ & 4427 & 3 & 0.68 & $0.14-1.98$ & 5 & $1 \cdot 13$ & $0.37-2.64$ & 8 & 1.81 & $0.78-3.56$ \\
\hline
\end{tabular}

Table 2 Age adjusted* incidence of myocardial infarction (MI) and angina pectoris in relation to cigarette smoking

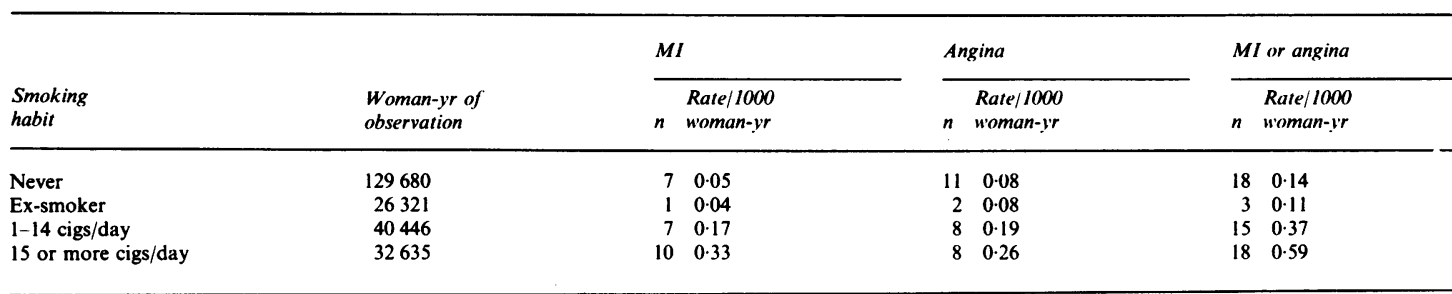

*By indirect standardisation 
All other variables were examined for their effect on disease incidence after adjustment for the effects of age and smoking. There were no consistent differences in adjusted incidence rates between social classes. However, table 3 demonstrates a progressive increase in adjusted disease incidence with parity and, to a lesser extent, with increasing body mass. As illnesses identified during follow-up are confined to hospitalisations, data on hypertension are incomplete, and it is not possible to assess formally the extent to which the influence of body mass is exercised through raised blood pressure.

The influence of oral contraceptive use is shown in tables 3 and 4 . The results of the case-control analysis accord with those of the prospective analysis. Although none of the effects achieves statistical significance, women with any oral contraceptive use appear to be at about twice as high a risk of myocardial infarction as never users, and at a reduced risk of angina. Current users are at lower risk of both myocardial infarction and angina than past users; this is particularly marked in relation to angina. There was some evidence that women were taken off the pill because they exhibited characteristics, other than age and smoking, which made them at higher risk of ischaemic heart disease. Thus, of the 13 women with myocardial infarction in the ex-user category, five are known to have changed from oral contraception for medical reasons (4 with raised blood pressure and 1 with unexplained lower abdominal pain).

The case-control analysis was performed to try to assess the effect of oestrogen dose. Table 4 shows that

Table 3 Incidence of myocardial infarction (MI) and angina pectoris, adjusted for age and smoking*, in relation to parity, Quetelet's index, and oral contraceptive use

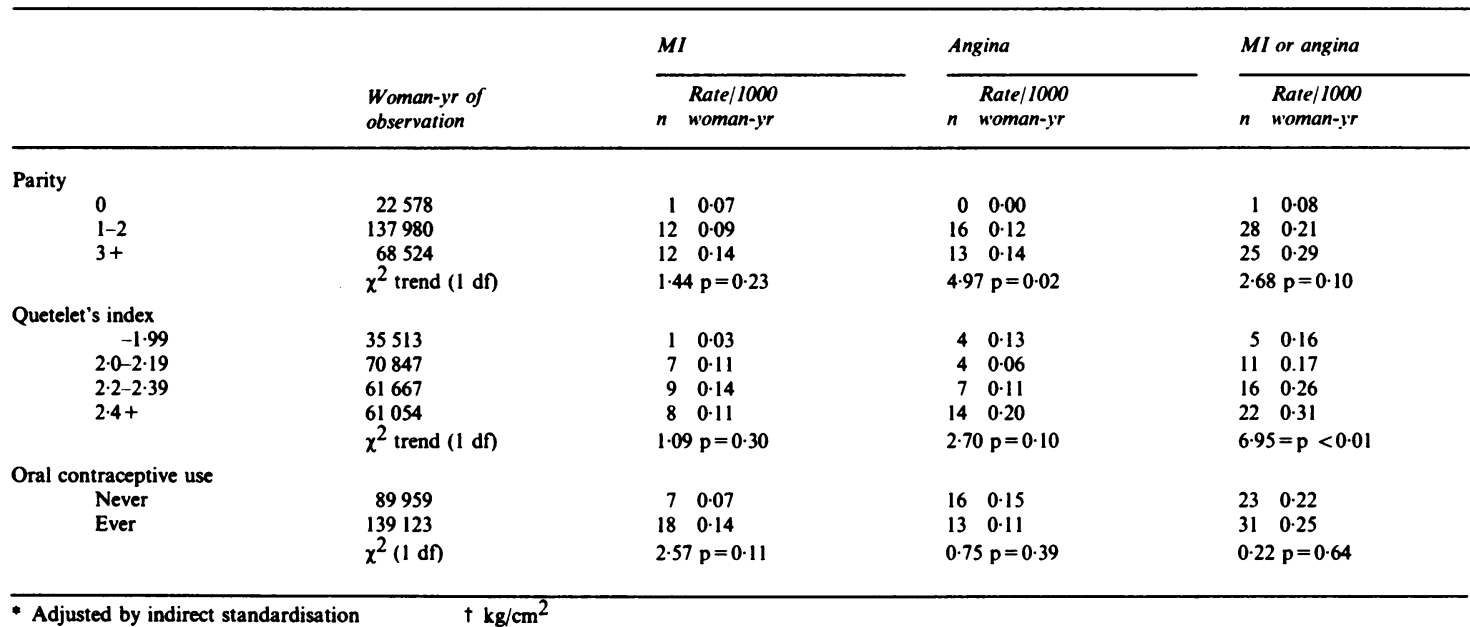

Adjusted by indirect standardisation

(age 5 groups, smoking 4 groups)

Table 4 Relative risk of myocardial infarction (MI) and angina pectoris according to oral contraceptive use: case-control analysis

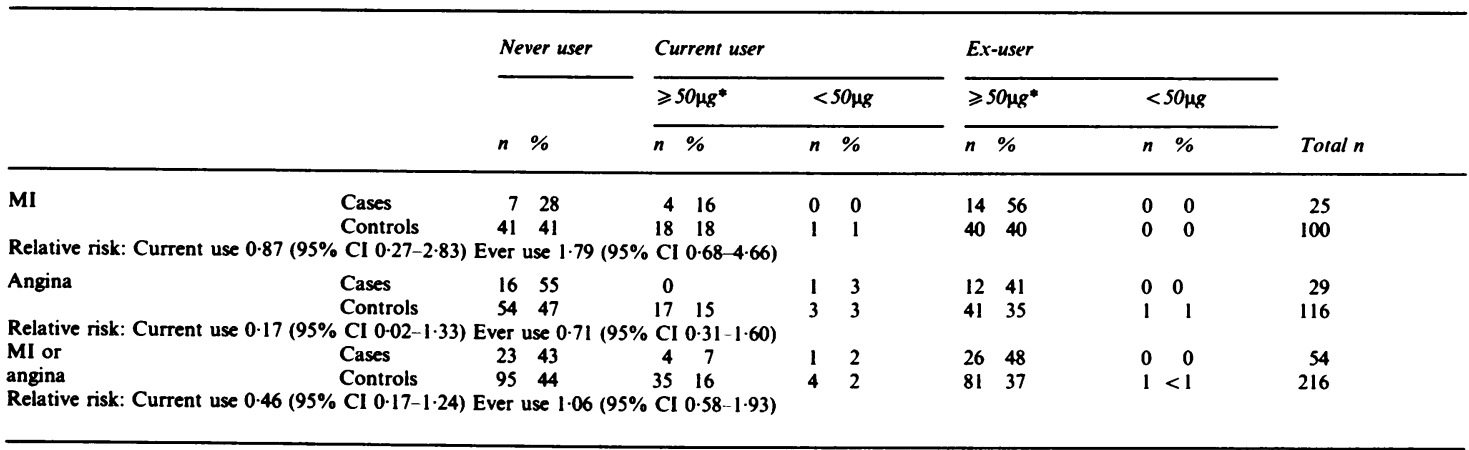


no cases of myocardial infarction and only one of angina have been reported in women using preparations containing less than $50 \mu \mathrm{g}$ oestrogen. However, as the use of $<50 \mu$ goestrogen pills was also at a very low level in the control group, it is impossible to draw any firm conclusions from the data. Similarly, the data were too few to allow assessment of the progestogen content of oral contraceptives.

\section{Discussion}

The age specific incidence of myocardial infarction observed in this study is comparable to that reported by the Walnut Creek group (0.02/1000 woman-years at ages 18-39 and 0.24/1000 woman-years at ages 40-49). 9 Age specific rates have not been published from the RCGP study, nor are there reliable comparative age specific incidence rates for young women from the population and community studies cited previously. In addition, the immediate case fatality rate for acute myocardial infarction in this study was $24 \%$ ( 6 cases out of 25 ). This compares with a case fatality rate of $26 \%$ ( 9 out of 34 cases) reported in women with acute ischaemic heart disease aged under 50 recruited to a community study in Helsinki. ${ }^{3}$ Once again there are few comparable data, although it is of interest that the case fatality rate in women aged 50 or over in the Helsinki study was higher (38\%: 107 out of 279 cases). It therefore appears possible that the low mortality rates from ischaemic heart disease in women reflect both a low incidence of acute myocardial infarction and a better chance of survival.

The strong relation we have demonstrated between smoking and both myocardial infarction and angina supports the findings in the many case-control studies on this subject. ${ }^{8}$ Rosenberg et al ${ }^{12}$ estimated recently the relative risk of myocardial infarction in female smokers aged under 50 years : the figures they obtained (1.4-7.0, according to amount smoked) are closely comparable to our findings ( 3 for light and moderate smokers and 6 for heavy smokers). The similarity in rates between non-smokers and exsmokers may reflect the fact that smoking status was recorded at entry to the study 12 to 18 years ago.

The positive relation between parity and ischaemic heart disease was also noted in a recent report from the Framingham Study ${ }^{14}$ and by Bengtsson in Oslo. ${ }^{15}$ However, in both studies the effect was limited to women with three or more pregnancies, and in Bengtsson's data it was statistically significant only for a subgroup of women with angina pectoris and five or more pregnancies. The reason for a possible effect of parity is not clear: both hormonal and psychological explanations have been advanced.

The influence of body mass, and the difficulty in interpreting this finding without adequate information on hypertension, has been referred to already. It is known that high body mass is positively associated with other cardiovascular risk factors, including hypertension, diabetes, and hyperlipidaemia, and body mass may be simply an indirect indicator of risk. The results of case-control studies have been conflicting. ${ }^{8}$ However, an association between body weight and the incidence of myocardial infarction and angina pectoris has also been reported in the longer term follow-up of the Framingham study. ${ }^{3}$ After 24 years, there is a definite positive trend in women in all age cohorts, and, in addition, the average age of onset of symptoms has been earlier the greater the relative weight.

The results presented on the effect of oral in contraceptives are essentially reassuring. As in other studies, there is no suggestion of a relation between oral contraceptive use and angina, and, in accordance with the findings of Adam et al ${ }^{16}$ our data suggest that the risk to current users is lower than was suggested by earlier studies. ${ }^{17}$ This presumably reflects the adoption of lower dose preparations (i.e. $50 \mu \mathrm{g}$ oestrogen or less) and the positive selection of healthier women for orat $i$ contraception. The importance of the latter effect ig $\vec{v}$ the interpretation of the comparative risk of high an ${ }^{+}$의 low oestrogen dose, and of time trends in the overaf risk of oral contraceptive use, must be stressed? Additionally, the elevated rate of myocardiat infarction observed in ex-users is consistent with the fact that women who develop risk factors foi cardiovascular disease (e.g. hypertension) are advise to stop taking oral contraceptives.

In summary, our results confirm that the annual risk of myocardial infarction and angina in young women in the United Kingdom is very low. For myocardial infarction this risk is in the order of 1 in 30000 at ages 25-34. Smoking increases the risk of myocardial infarction by up to sixfold, depending on the number of cigarettes smoked. Body weight and parity may also be related to risk, although the mechanism of causation is likely to be complex. The evidence on oral contraceptive use is more encouraging than earlier reports based on case-control studies. The observed relative risk in ever users is less than twofold, and no women in the study have suffered a myocardial infarction while taking preparations containing less than $50 \mu \mathrm{g}$ oestrogen.

We thank Mrs P Brown, Mrs C Brice, our research assistants, and the staff of the participating clinics for their continued loyal support. We also thank the Medical Research Council for financial help. 


\section{References}

${ }^{1}$ Stephens WB. Myocardial infarction-incidence in Alburg-Wodonga. Med J Aust 1970; 2: 446-52.

2 Pole DJ, McCall MG, Reader R, et al. Incidence and mortality of acute myocardial infarction in Perth, Western Australia. J Chron Dis 1977; 30: 19-27.

${ }^{3}$ Dawber TR. Incidence of coronary heart disease, stroke and peripheral arterial disease. In Dawber TR, Ed. The Framingham Study: the epidemiology of atherosclerotic disease. Cambridge: Harvard University Press, 1980; 59-75.

${ }^{4}$ Elmfeldt D, Wilhelmson L, Tibblin G, et al. Registration of myocardial infarction in the City of Goteborg, Sweden: a community study. J Chron Dis 1975; 28: 173-186.

5 Johannson S, Vedin A, Wilhelmsson C, Wedel $\mathrm{H}$, Wilhelmsen L. Myocardial infarction among women in Goteborg, Sweden: a community study of mortality and incidence, 1968-77. Am j Epidemiol 1984; 119: 603-9.

${ }^{6}$ Pell S, d'Alonzo CA. Acute myocardial infarction in a large industrial population: report of a 6 year study of 1356 cases. JAMA 1963; 185: 831-8.

${ }^{7}$ Shapiro S, Weinblatt E, Frank CW, et al. Incidence of coronary heart disease in a population insured for medical care (HIP): myocardial infarction, angina pectoris, and possible myocardial infarction. Am J Publ Hlth 1969; 59: (Suppl 6), 1-101.

8 Johannson S, Vedin A, Wilhelmsson C. Myocardial infarction in women. Epidemiologic Reviews 1983; 5: 67-95.
${ }^{9}$ Ramcharan S, Pellegrin FA, Ray R, Hsu J-P. The Walnut Creek Contraceptive Drug Study: an interim report. Centre for Population Research Monograph, NIH Publication No. 81-564 (January 1981)

${ }^{10}$ Oral Contraceptives and Health: An Interim Report from the Oral Contraceptive Study of the Royal College of General Practitioners. New York: Pitman Medical, Pitman Publishing Corporation 1974.

${ }^{11}$ Vessey M, Doll R, Peto R, Johnson B, Wiggins P. A long term follow-up of women using different methods of contraception - an interim report. J Biosoc Sci 1976; 8: 373-437.

12 Romo M. Factors related to sudden death in acute ischaemic heart disease. Acta Med Scand 1972; Suppl. 547: 1-92.

${ }^{13}$ Rosenberg L, Kaufman DW, Helmrich SP, et al. Myocardial infarction and cigarette smoking in women younger than 50 years of age. JAMA 1985; 253: 20, 2965-9.

${ }^{14}$ Haynes SG, Feinleib M. Women, work and coronary heart disease: prospective findings from the Framingham Study. Am J Publ Hlth 1980; 70: 133-41.

${ }^{15}$ Bengtsson C. Ischaemic heart disease in women. Acta Med Scand 1973; 549: (Suppl), 1-128.

${ }^{16}$ Adam SA, Thorogood M, Mann JI. Oral contraception and myocardial infarction revisited: the effects of new preparations and prescribing patterns. $\mathrm{Br} J$ ObstetGynaec 1981; 88: 838-45.

${ }^{17}$ Mann JI, Doll R, Thorogood M, Vessey MP, Waters WE. Risk factors for myocardial infarction in young women. Br J Prev Soc Med 1976; 30: 94-100. 